doi:10.17659/01.2019.0039

Journal of Case Reports 2019;9(3):149-151

\title{
Radial Head Excision and Transcapitellar Fixation: Efficient Modality for Congenital Radial Head Dislocation at Adolescent Age
}

\author{
Rishit Soni, Krunal Shah, Prasanna Shah, Jay Turakhiya, Parth Rathi, Paresh Golwala \\ Department of Orthopaedics, SBKS \& MIRC, Sumandeep Vidyapeeth University, Piparia, Vadodara, Gujarat, India.
}

\section{Corresponding Author:}

Dr. Krunal Shah

Email id: dr.krunalshah08@yahoo.com

This is an Open Access article distributed under the terms of the Creative Commons Attribution License (creativecommons.org/ licenses/by/3.0).

$\begin{array}{lll}\text { Received } & : & \text { May 22, 2019 } \\ \text { Accepted } & \text { : } & \text { June 16, 2019 } \\ \text { Published } & : & \text { July 20, 2019 }\end{array}$

\begin{abstract}
Background: Congenital dislocation of the radial head of the elbow is genetically transmitted in some cases and is often associated with syndromes, such as Nail-Patella syndrome, antecubital pterygium and ulnar dysplasia. The natural history of the condition is that symptoms are relatively benign, with only some limitation of motion and deformity. Treatment either involves early attempts at reconstruction or delayed intervention at skeletal maturity with radial head excision. Case Report: We evaluated the radiographic and functional results of radial head excision and transcapitellar K-wire fixation in the treatment of unilateral left side congenital dislocation of the radial head in 15 year old girl with excellent result at final follow-up. Conclusion: Congenital radial head dislocation should be treated with open reduction and internal fixation with/without radial shortening at an earlier age but if untreated/neglected till adolescence, radial head excision after proper evaluation can give excellent results.
\end{abstract}

Keywords: Bone Wires, Elbow Joint, Joint Dislocation, Musculoskeletal Abnormalities, Radius.

\section{Introduction}

Radial head dislocation can be congenital, developmental or post-traumatic [1,2]. Congenital dislocation of the radial head of the elbow is rare. It is genetically transmitted in some cases and is often associated with syndromes, such as NailPatella syndrome, antecubital pterygium and ulnar dysplasia [3-5]. About two thirds are posterior, with the remainder being either anterior $(15 \%)$ or lateral (15\%) [2]. Developmental dislocation of radial head may occur in children with hereditary multiple osteochondromatosis or diaphysial aclasis. The radial head subluxates as consequences of retarded growth of the ulna. If the relative length of radius and ulna are not restored, radial head will dislocate. Although isolated developmental radial head dislocation has been described, most often subtle injury to ulna is also present.
There are various treatment options available for the same including open reduction, radial shortening, reconstruction of annular ligament, gradual lengthening of ulna and indirect reduction of radial head and radial head excision and transcapitellar fixation. We present a case of a developmental dislocation of radial head in a 15 year old young female patient. Informed consent was obtained from the patient for this study.

\section{Case Report}

We report a 15 year young female patient who presented with pain over left elbowjoint since 4 years of age, pain was aggravated since last 15 days. The pain was a dull ache, mild in intensity without any diurnal variation. A physical examination revealed mild tenderness locally with overlying normal skin, affected elbow joint movement: restricted supination (upto $60^{\circ}$ ) and restricted extension with 
all other movements normal and there was bony hard swelling. The laboratory investigations were within normal limits. A radiographic examination showed posterior dislocated radial head without any evidence of ulna involvement or features of osteochondromatosis/diaphyseal achalasia. After taking consent from the patient radial head excision [Fig.1] and transcapitellar K-wire fixation was done under general anaesthesia [Fig.2] and post-operatively patient was immobilized in above elbow slab with maximum supination $\left(70^{\circ}\right)$ possible. After suture removal on post operativeday 12 , patient was given above elbow cast with elbow in $90^{\circ}$ flexion and $70^{\circ}$ of supination for 1 month. After 6 weeks, transcapitellar K-wires were removed [Fig.3] and mobilization was started.

The patient was assessed at regular intervals. At follow-up of 3 months, in sagittal plane 30-100 degrees range of motion and 0-90 degrees pronation and supination of 0-80 degrees was achieved.

\section{Discussion}

Congenital dislocation of the radial head is the most common congenital elbow abnormality [6] and usually occurs in association with other conditions ( $60 \%$ of the time), but can also occur in isolation [7]. The more common associated conditions include lower extremity anomalies, scoliosis, mental retardation, and nail-patella and Klippel-Feil syndromes [8]. The condition is usually bilateral, but some unilateral cases have been described [8,9]. When unaccompanied by other radial or systemic conditions, it is almost always bilateral. It is often not noted until the age of four or five at which time some limitation of motion or deformity becomes evident [10].

The dislocation of radial head and its associated features are now believed to be triggered by failure of development of a normal capitulum, which deprives the developing radial head of the
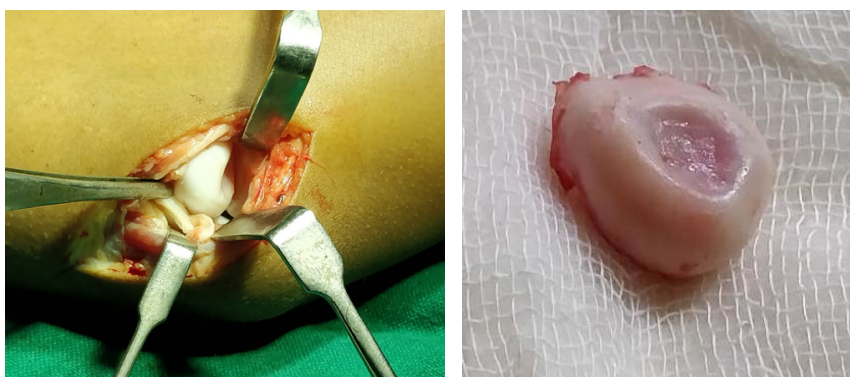

Fig.1: Approach and excised radial head.

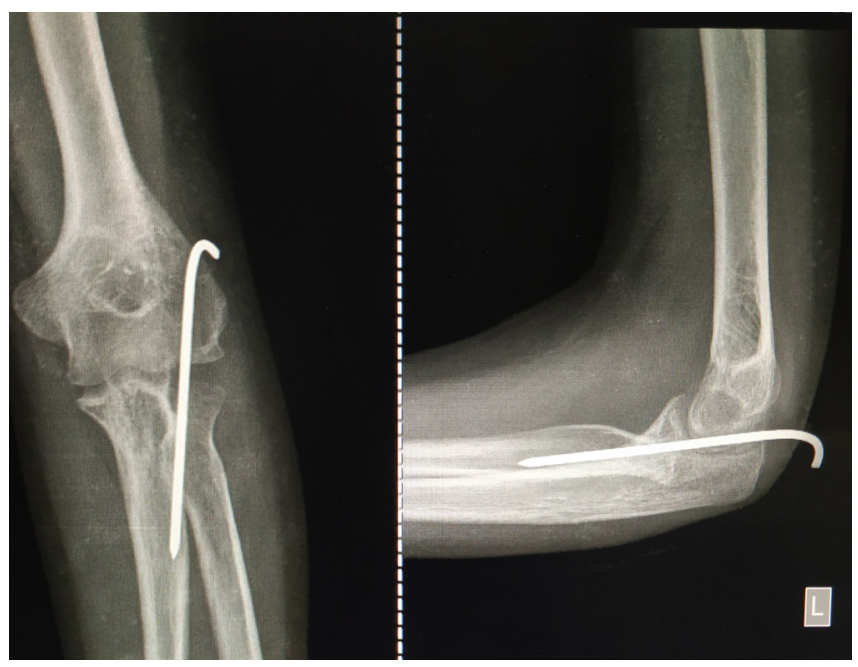

Fig.2: $X$-ray image of transcapitellar K-wire fixation.

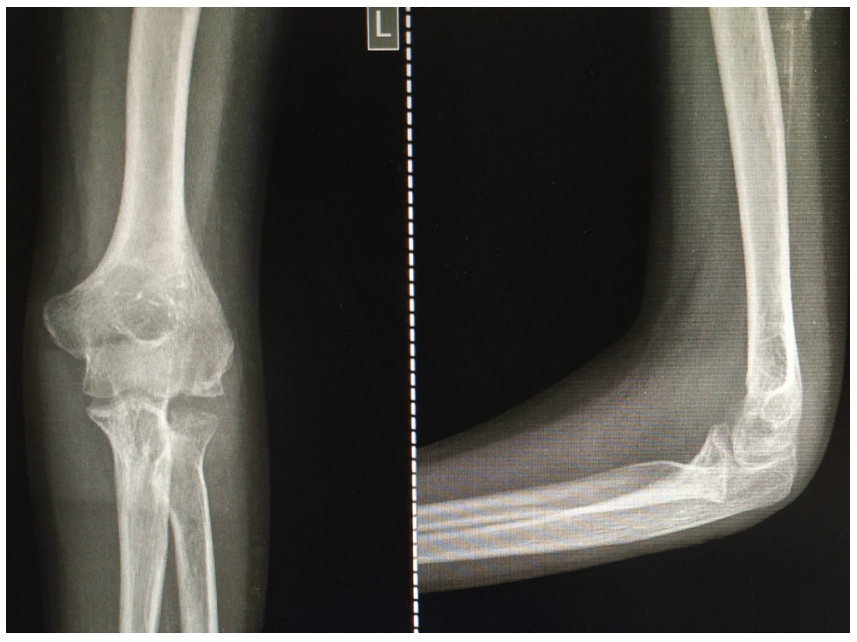

Fig.3: X-ray image after $K$-wire removal. 
contact pressure required for normal development and results in malformation of the radiocapitellar joint [11]. The symptoms are relatively benign, with only some limitation of motion and deformity [12]. Early radiographic findings are subtle due to the absence of the capitulum and radial head ossification centers [12]. Before radial head ossification ( $\sim$ five years) a line drawn along the shaft of the radius should normally bisect the capitulum ossification center (McLaughlin's line) which was not seen in this case [13].

Generally, patients become symptomatic by adolescence and are treated by radial head resection. Surgery at an earlier age with open reduction and ligament reconstruction may offer advantages over late radial head resection [6]. Early reconstruction may prevent the long term complication of pain, loss of motion, deformities and osteochondral loose bodies [14]. Ideally the care of congenital dislocation of the radial head would involve open reduction and restoration of normal anatomy. The logic is that if the radial head can be reduced early, the deformity of the capitulum and the forearm may not occur or remodel with growth [14].

\section{Conclusion}

At an earlier age, open reduction and fixation of congenital radial head dislocation with/without radial shortening is the treatment of choice but in adolescence age, radial head excision after proper evaluation can also give excellent results.

Contributors: RS, KS: manuscript writing, patient management and diagnosis; PS, JT, PR manuscript editing and patient management. PG: critical inputs into the manuscript and supervised the patient care. KS will act as a study guarantor. All authors approved the final version of this manuscript.

Funding: None; Competing interests: None stated.

\section{References}

1. Amadio PC, Dobyns JH. Congenital abnormalities of the elbow. In: Morrey BF, Sanchez-Sotelo J (eds) The elbow and its disorders. Saunders, Philadelphia, 2009; pp. 184205.

2. Mardam-Bey T, Ger E. Congenital radial head dislocation. J Hand Surg Am. 1979;4:316-320.

3. Kelly DW. Congenital dislocation of the radial head:spectrum and natural history. J Pediatr Orthop. 1981;1:295-298.

4. Agnew DK, Davis RJ. Congenital unilateral dislocation ofthe radial head. J Pediatr Orthop. 1993;13:526-528.

5. Miura T. Congenital dislocation of the radial head. J Hand Surg Br. 1990;15:477-481.

6. Sachar K, Mih AD. Congenital Radial Head Dislocations. Hand Clin. 1998;14(1):39-47.

7. Joseph PI, Richard P. The Netter Collection of Medical Illustrations: Musculoskeletal System Volume 6, Part I - Upper Limb: Elsevier Health Sciences, Medical. 2012; (6):104.

8. Agnew DK, Davis RJ. Congenital unilateral dislocation of the radial head. J Pediatr Orthop.1993;13(4):526-528.

9. Echtler B, Burckhardt A. Isolated congenital dislocation of the radial head. Good function in 4 untreated patients after 14-45 years. Acta Orthop Scand. 1997;68(6):598600.

10. Hughes T, Chung CB: Bone and Cartilage Injury, Chapter 12. In: Chung CB and Steinbach LS (editors). MRI of the upper extremity: shoulder, elbow, wrist, and hand. Lippincott Williams \& Wilkins; Philadelphia, USA. 2010;487-488.

11. Maresh MA. Linear growth of long bones of extremities from infancy through adolescence; continuing studies. AMA Am J Dis Child. 1955;89(6):725-742.

12. Kelly DW. Congenital dislocation of the radial head: spectrum and natural history. J Pedatr Orthop. 1981;1(3):295-298.

13. Miles KA, Finlay DB. Disruption of the radiocapitellar line in the normal elbow. Injury. 1989;20(6):365-367.

14. Wood WL, Robert BW, Raymond TM, Weinstein SL. Weinstein. Lovell and Winter's Pediatric Orthopaedics, Volume 2; Lippincott Williams \& Wilkins, Medical. 2006;2:935. 